\title{
Quantification over Times in Subjunctive Conditionals
}

\author{
Michela Ippolito \\ UCSC/Tübingen University
}

In this paper I will propose a compositional semantics for counterfactuals motivated by the need to solve some puzzles that I will shortly discuss. The main thesis is that the puzzles of counterfactuals can be understood once we unveil the hidden quantification over times. I will propose that the essential feature of a counterfactual is the presence above the modal operator of temporal and aspectual operators manipulating the time argument of the accessibility relation. In section I will discuss the puzzles of counterfactuals; and in sections (12) and (23) I will present my proposal.

\section{The puzzle of counterfactuals}

According to Kratzer's semantics for conditionals, there are two parameters that contribute to the interpretation of the modal, a modal base and an ordering source (Kratzer (1991), Kratzer (1981)). Symplifying Kratzer's proposal, a modal base is a set of worlds $w$ where all the propositions in the conversational background are true: if $R_{w}$ is the conversational background - a function that assigns to $w$ a certain set of propositions - the modal base is $\bigcap R(w)$. An ordering source is a function that ranks all the worlds in the modal base according to how close they get to some "ideal" in the evaluation world (where the "ideal" is also a set of propositions). To illustrate this system, let us briefly consider the Kratzerian analysis of the epistemic indicative conditional in (1).

(1) If Jack is reading a book, it must be a novel.

$R$ is epistemic and assigns to the evaluation world $w$ the set of propositions that the speaker knows in the evaluation world $w$, so that the modal base 
$\bigcap R(w)$ is the set of worlds where all the speaker knows in $w$ is true. The ordering source is stereotypical: the accessible worlds (the worlds in the modal base) are ranked according to how close they get to the speaker's stereotypes in the evaluation world $w$. In the tree below, $R$ is the modal base, $G$ is the ordering source. Kratzer's proposal for counterfactuals is that $R$ is empty and, consequently, the modal base is $W$. As for the ordering source, it is totally realistic.

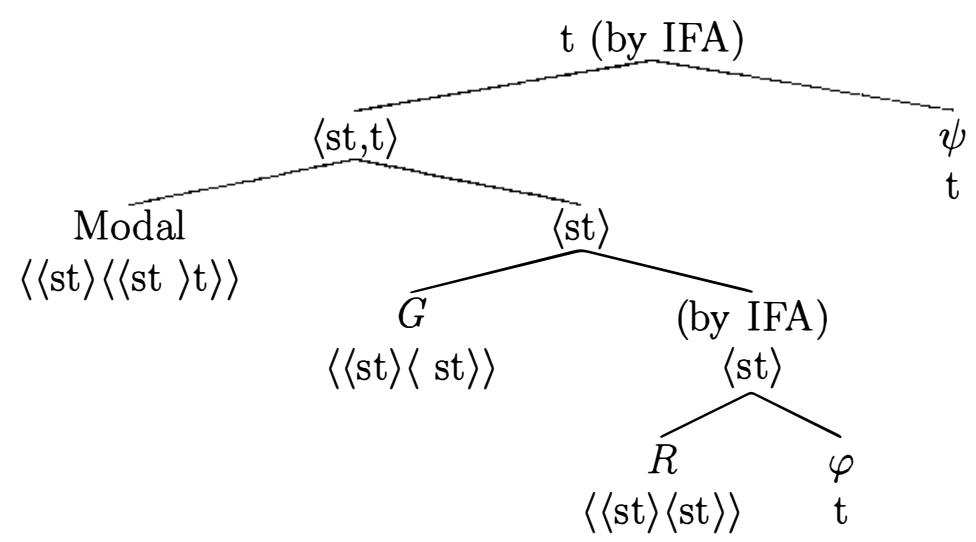

Lewis (1973)'s analysis of counterfactuals is similar in spirit to what we have just described. For Lewis too, there are two parameters that enter into the evaluation of the truth-conditions of a counterfactual: a system of spheres of accessibility (w.r.t. to an evaluation world $w$ ), and a comparative similarity relation $\leq_{w}$, ranking accessible worlds according to how similar they are to the evaluation world $w$.

The reason for having a large modal base, $W$, is that the antecedent of a counterfactual is typically known to be inconsistent with what is assumed to be true.

Jack is dead.

If Jack were alive, he would be a hundred years old.

However, when the antecedent of a counterfactual carries a presupposition trigger, the presupposition in the antecedent cannot be inconsistent with the common ground. I will assume with Musan (1997) that most predicates carry a presupposition that their subjects be in existence or alive at the time when the predicate is said to hold of them. For instance, to say that $x$ attends $y$ at $t$ presupposes that $x$ is alive at $t$, as shown below. 
(4) 【attend $\rrbracket^{c, g, w, t}(\mathrm{x})(\mathrm{y})$ is defined only if $x$ is alive at $t$ in $w$; if defined, 【attend $\rrbracket^{c, g, w, t}(\mathrm{x})(\mathrm{y})=1$ iff $x$ attends $y$ at $t$ in $w$.

(5) Jack is dead.

\# If Jack attended commencement this summer, he would meet the new Dean.

The infelicity of (5) cannot be due to the counterfactuality of the antecedent, since (3) is felicitous. In Kratzer's and Lewis's theories of counterfactuals, we look for possible worlds that differ from the actual world as much as it is required by the truth of the antecedent. Because these theories make no distinction between what the antecedent supposes and what is presupposes, (3) and (5) are treated in the same way. In both, we must select counterfactual worlds where Jack will attend commencement this summer, and in both the minimal change (with respect to the actual world) necessary to guarantee consistency is that in these worlds Jack did not die when he actually did and will be still alive at the time of the commencement. Consequently, (3) and (5) are both predicted to be felicitous. In fact, following Kratzer's and Lewis's recipe for counterfactuals, (5) is expected to be as felicitous as the following counterfactual conditional.

Jack is dead.

If Jack were alive and attended the commencement this summer, he would meet the new Dean.

What the contrast between (5) and (6) shows is that to treat the proposition that Jack will be alive at the time of the commencement as part of the supposition (the antecedent) itself is not correct. As we already hinted above, the proposition that Jack will be alive at the time of the commencement must be treated as a presupposition. However, in the next section we will see that this is not straightforward as one might hope.

\subsection{Presuppositions in the antecedents of counterfactuals}

According to Stalnaker (Stalnaker (1978)), Karttunen (Karttunen (1974)), Heim (Heim (1982), Heim (1983)), propositions are sets of worlds and presuppositions are propositions. The operation of adding a proposition $\varphi$ to a context $c$ (also a set of worlds) amounts to intersecting $p$ and $c$ and this operation is only defined if $\varphi$ 's presuppositions, ps $(\varphi)$, are entailed by $c$. However, as pointed out in Heim (1992), when we combine this theory of presupposi- 
tions with Kratzer/Lewis's analyses of counterfactuals, we run into problems. The framework developed in Heim (1992) is Context Change Semantics. The main thesis is that the meaning of a sentence is its context change potential (CCP), i.e. a function from contexts to contexts. In order to illustrate how this works, considers Heim's proposal for the context change potential of an indicative conditional.

$$
\begin{aligned}
& \text { CONTEXT CHANGE POTENTIAL FOR INDICATIVE CONDITIONALS: } \\
& c+i f \varphi, \psi=\left\{w \in c: \operatorname{SIM}_{w}(\underline{c+\varphi})+\psi=\operatorname{SIM}_{w}(c+\varphi)\right\}
\end{aligned}
$$

The CCP in (7) is the rendition of Stalnaker (1975)'s proposal that the pragmatic constraint at work in indicative conditionals is that the selection function must select an antecedent-world inside the context set, i.e. inside the set of worlds modeling the information state of the participants in the conversation. ${ }^{1}$ In (7), the antecedent $\varphi$ is added to the context set $c$ and the worlds that are selected are those $\varphi$-worlds inside $c$ that are most similar to what we take the actual world to be. ${ }^{2}$ By assuming that when a function takes the empty set as is argument it is undefined, we guarantee that an indicative conditional is only felicitous if $\varphi$ is compatible with the context set, and if $\varphi$ 's presuppositions are entailed by the context set. Let us now turn to counterfactuals. If we couch Kratzer's claim that the modal base in counterfactual is $W$ within Heim's theory, we run into problems.

$$
\begin{aligned}
& \text { Problematic CCP for counterfactuals: } \\
& \mathrm{c}+\text { if } \varphi, \psi=\left\{w \in c: \operatorname{SIM}_{w}(\underline{W+\varphi})+\psi=\operatorname{SIM}_{w}(c+\varphi)\right\}
\end{aligned}
$$

(8) is what the CCP for a counterfactual would have to look like: the context set $c$ has been replaced by the set of all possible worlds $W$, precisely to capture the fact that the antecedent may be counterfactual. However, as Heim points out, the CCP in (8) incorrectly predicts that a counterfactuals whose antecedent carries a presupposition should be undefined, since the operation of adding $\varphi$ to $W$ is always undefined because $W$ cannot have the right entailment. The counterfactual in (9) is felicitous despite the fact that its antecedent carries the presupposition that somebody other than Jack is in the room.

(9) $\mathrm{John}_{i}$ is the only person in the room.

If $\mathrm{Jack}_{F}$ were in the room too ${ }_{i}$, it would be loud. 
Heim's solution is to revise the context set so that some assumptions are dropped (in order to be compatible with the counterfactual antecedent), but some assumptions are kept (in order to entail the antecedent's presuppositions). The result is a superset of $c$, defined as follows.

For any context c, $\operatorname{LF} \varphi$ : $\operatorname{rev}_{\varphi}(\mathrm{c})$, the revision of $\mathrm{c}$ for $\varphi$, is $\bigcup\{\mathrm{X} \subseteq \mathrm{W}: \mathrm{c} \subseteq \mathrm{X}$ and $\underline{\mathrm{X}}+\varphi$ is defined $\}$

The new CCP for a counterfactual conditional will look as in (11).

CONTEXT CHANGE POTENTIAL FOR COUNTERFACTUALS: $\mathrm{c}+$ if $\varphi$, would $\psi=\left\{w \in c: \operatorname{SIM}_{w}\left(\underline{\operatorname{rev}_{\varphi}(c)+\varphi}\right)+\psi=\operatorname{SIM}_{w}(c+\varphi)\right\}$

Since $c \subset \operatorname{rev}_{\varphi}(c)$, requiring that $\operatorname{rev}_{\varphi}(c) \subseteq \operatorname{ps}(\varphi)$ guarantees that $c \subseteq \operatorname{ps}(\varphi)$, thus accounting for the infelicity of (5).

As Heim herself points out, though, this solution seems rather stipulative: the revision of the context set is not motivated independently and the requirement that $\operatorname{ps}(\varphi)$ be entailed by $c$ is simply added as a condition on the way the revision of the context set is obtained. Furthermore, Heim's proposal does not account for the contrast between what elsewhere I called one past and two pasts counterfactuals (Ippolito (2003b), Ippolito (2003a)).
a. One Past COUNTERFACTUAL Jack died last year. \#If Jack attended commencement this summer, he would meet the new Dean.
b. Two Pasts COUNTERFACTUAL
Jack died last year.
If Jack had attended commencement this summer, he would have met the new Dean.

The two counterfactuals above are morphologically different, and have different felicity conditions as witnessed by the fact that (12-b) is felicitous even though $\operatorname{ps}(\varphi)$ is counterfactual too (Jack will be dead at the time of the commencement). If we give the CCP for (12-b) following the recipe in (11), (12-b) should come out infelicitous, since $\operatorname{ps}(\varphi)$ (that Jack will be alive this summer) are not entailed by the context set. As it is, Heim's solution does not account for this contrast. 


\section{The proposal}

The objective of this paper is to derive the projection properties of presuppositions in both one past and two pasts counterfactuals from the quantification over times hidden in their structure. By doing so, we will address the question: What are the necessary components of counterfactuals that distinguish them from indicative conditionals?

(13) If Jack attends commencement this summer, he will meet the new Dean.

(14) If Jack attended commencement this summer, he would meet the new Dean.

Instead of conversational backgrounds, I will talk about accessibility relations. ${ }^{3}$ I take the accessibility relation in counterfactuals to be metaphysical, and I take it to have a time parameter in addition to a world parameter. Let the accessibility relation MET be defined as follows.

$$
\begin{aligned}
& \llbracket \mathrm{MET} \rrbracket^{c, g, w, t}=\lambda p \in \mathrm{D}_{<i<s t>>} \cdot \lambda w^{\prime} . w^{\prime} \text { has the same history as } w \text { up } \\
& \text { to } t \text { and } \mathrm{p}\left(w^{\prime}\right)(t)=1 .
\end{aligned}
$$

The second parameter for the evaluation of a conditional sentence is an overall similarity function SIM, defined in (16). ${ }^{4}$ The entry for the modal operator WOLL is given in (17).

$$
\begin{aligned}
& \llbracket \operatorname{SIM} \rrbracket^{c, g, t, w}=\lambda p \in \mathrm{D}_{<s t>} \cdot \lambda w^{\prime} \cdot \mathrm{p}\left(w^{\prime}\right)=1 \text { and } \neg \exists w^{\prime \prime}\left[\mathrm{p}\left(w^{\prime \prime}\right)=1\right. \text { and } \\
& \left.w^{\prime \prime} \text { is overall more similar to } w \text { than } w^{\prime}\right] . \\
& \llbracket \mathrm{WOLL} \rrbracket^{c, g, t, w}=\lambda p \cdot \lambda q . \forall w^{\prime}\left[\mathrm{p}\left(w^{\prime}\right) \rightarrow \mathrm{q}\left(w^{\prime}\right)\right] .
\end{aligned}
$$

I will be using an intensional semantics and I will make the assumption that sentences are evaluated with respect to two times, one which I will call the evaluation time, and the other which I will call the event time. To illustrate this point, consider the sentence Jack attended commencement as uttered now: the evaluation time is the speech time; the event time is the past time at which Jack attended commencement. In this particular example, the past tense manipulates the event time. However, tenses can also manipulate the evaluation time, as in the more complex sentence $A$ week ago Jack said that John would call yesterday: the time of evaluation of the embedded clause is not the speech time (the calling is not located in the future), but the past time 
at which Jack's utterance was made. ${ }^{5}$ As will become clearer shortly below, my proposal is that temporal operators can manipulate the time argument of the accessibility relation, which is the time at which the antecedent and the consequent propositions are evaluated.

\subsection{Quantification over times}

The structure of a one past counterfactual If Jack attended commencement this summer, he would meet the new Dean is the structure of a "bare" conditional ${ }^{6}$ embedded under the structure of a universal perfect, as shown in (18).

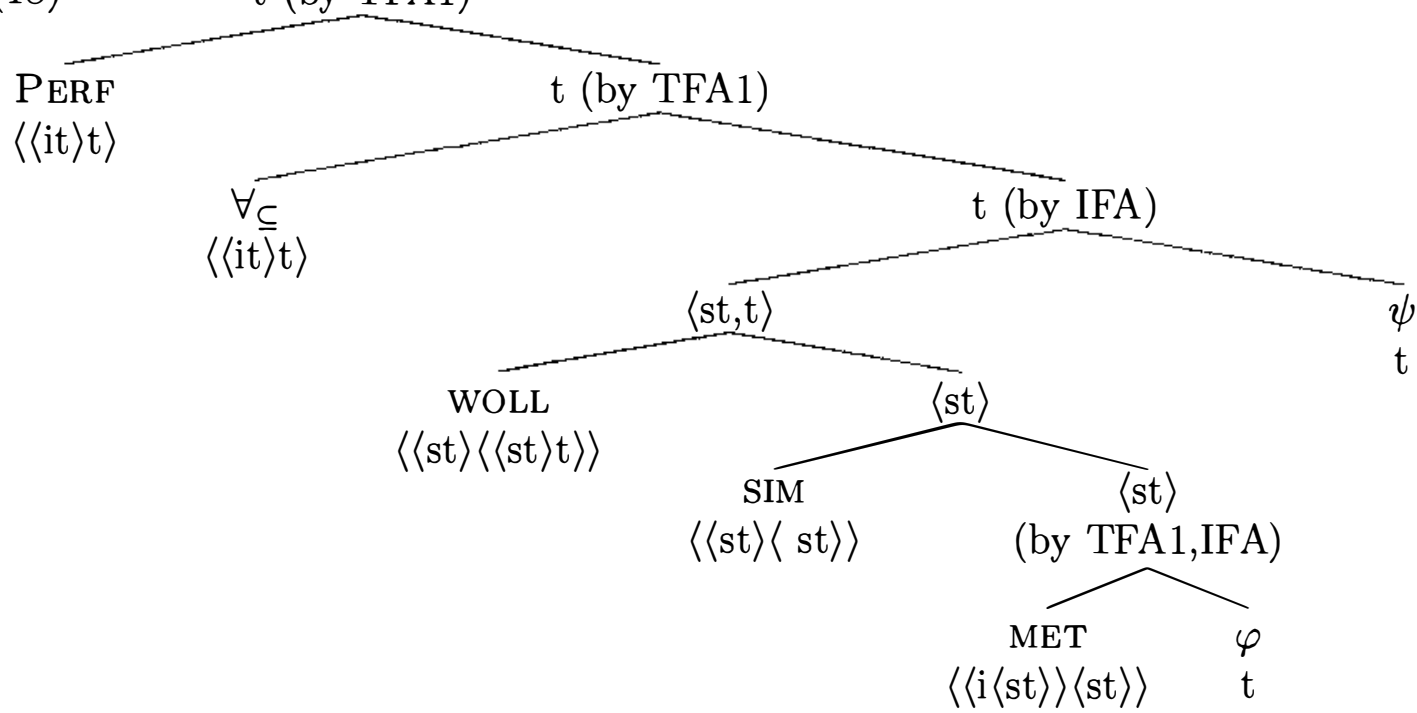

Let us backtrack a little. The view of the perfect that I have in mind is taken from Fintel and Iatridou (2002), and is an elaboration of Dowty (1979)'s Extended Now theory of the perfect. According to Fintel and Iatridou (2002), the LF of the universal perfect sentence in $(19-\mathrm{a})$ is $(19-\mathrm{b}) .^{7}$

a. John has been pitching since 1998.

b. $\llbracket\left[{ }_{T P}\right.$ PRES [PERF since $1998\left[\right.$ [AspP IMP [VP John pitch]]]] $\rrbracket^{c, g, w, t}$ $=1$ iff $\exists t: R B\left(t, t^{\prime}\right)$ and $L B\left(1998, t^{\prime}\right)$ and $\forall t^{\prime \prime} \subseteq t^{\prime}$ : John pitch in $w$ at $t^{\prime \prime}$.

PERF, the perfect operator, introduces a time interval, whose right boundary (RB) is determined by the c-commanding tense (Present in our example). 
IMP, the imperfective aspect, is interpreted as a universal quantifier over the subintervals of the perfect interval. ${ }^{8}$ The relevant definitions are given in (20).

$$
\begin{aligned}
& \llbracket \mathrm{PERF} \rrbracket^{c, g, t, w}=\lambda P_{<i t>} \cdot \exists t^{\prime}: R B\left(t, t^{\prime}\right) \text { and } \llbracket \mathrm{P} \rrbracket^{c, g, w}\left(t^{\prime}\right)=1 . \\
& \llbracket \forall \subseteq \rrbracket^{c, g, t, w}=\lambda P_{<i t>} \cdot \forall t^{\prime} \subseteq t: \llbracket \mathrm{P} \rrbracket^{w}\left(t^{\prime}\right)=1 .
\end{aligned}
$$

When PERF and $\forall_{\subseteq}$ are interpreted in the conditional structure in (18), we obtain the following truth-conditions. (See the Appendix for the outline of the derivation.) Since there is no tense above PERF, the RB will coincide with $t$, the evalaution time of the whole structure (i.e. the speech time).

【If Jack attended commencement this summer, he would meet the new Dean $\rrbracket^{c, g, w, t}=1$ iff

$\exists t^{\prime}: \operatorname{RB}\left(t, t^{\prime}\right) \wedge \forall t^{\prime \prime} \subseteq t^{\prime}\left[\forall w^{\prime}\left[w^{\prime}\right.\right.$ is metaphysically accessible from $w$ at $t^{\prime \prime} \wedge \exists t^{\prime \prime \prime} \succeq t^{\prime \prime}$ s.t. it is true in $w^{\prime}$ at $t^{\prime \prime}$ that Jack will attend commencement this summer at $t^{\prime \prime \prime} \wedge \neg \exists w^{\prime \prime}$ : $\left[w^{\prime \prime}\right.$ is metaphysically accessible fom $w$ at $t^{\prime \prime}$ and s.t. it is true in $w^{\prime \prime}$ at $t^{\prime \prime}$ that Jack will attend commencement this summer $\wedge w^{\prime \prime}$ is overall more similar to $w$ than $\left.w^{\prime}\right] \longrightarrow \exists t^{\prime \prime \prime \prime} \succeq t^{\prime \prime}$ s.t. it is true in $w^{\prime}$ at $t^{\prime \prime}$ that Jack will meet the new Dean at $\left.\left.t^{\prime \prime \prime \prime}\right]\right]$.

The important point in the proposal above is that when we evaluate a subjunctive conditional if $\varphi$, would $\psi$, we evaluate the bare conditional if $\varphi, \psi$ at each subinterval of the perfect interval. The subjunctive conditional if $\varphi$, would $\psi$ is true just in case at each subinterval the bare conditional if $\varphi, \psi$ is true. Let me spend a few words on the temporal interpretation of $\varphi$ and $\psi$. Since the bare conditional is evaluated at past subintervals as well as at the speech time, we must postulate a temporal operator in the structure of both $\varphi$ and $\psi$ so as to correctly interpret the future and present temporal adverbs that may occur in a one past counterfactual. I call this operator NON-PAST, and I assume it has roughly the following meaning. ${ }^{9}$

$$
\llbracket \text { NON-PAST } \rrbracket^{g, c, w, t,}=\lambda P_{<i, t>} \cdot \exists t^{\prime}\left[t^{\prime} \succeq t \text { and } \mathrm{P}(w)\left(t^{\prime}\right)=1\right]
$$

(18) is the structure of a one past counterfactual. The first significant outcome of this proposal is that it is a proposal about how to derive the truthconditions of a counterfactual compositionally, as shown in (22). As I will discuss in the next section, the second significant outcome of the proposal is 
that it sheds light on the puzzles of counterfactuals we began with, i.e. (i) the fact that despite the counterfactuality of the antecedent, the antecedent's presuppositions (if any) must hold not only in the antecedent-worlds but also in the actual world, and (ii) the contrast between one past and two pasts counterfactuals.

\section{Presupposition projection}

Consider the contrast between (24) and (25) again.

(24) Jack is dead.

If Jack were alive, he would be a hundred years old.

(25) Jack is dead.

\#If he attended commencement this summer, he would meet the new Dean.

To put it differently, the two facts that seem difficult to reconcile in a nonstipulative theory of counterfactuals are the following: (1) the antecedent $\varphi$ of a subjunctive conditional can be counterfactual, i.e. there may be no $\varphi$-world accessible from the actual world at the speech time; (2) however, even when $\varphi$ is counterfactual, $\operatorname{ps}(\varphi)$ cannot be counterfactual.

The objective of this section is to show that once we unveil the temporal quantificational structure in counterfactuals, the contrast above is reduced to the behavior of presupposition projection in other sentences with quantifiers in the same configuration.

In light of examples that we will discuss below, I claim that the following generalization holds.

ProjeCtion

a. If a quantifier $Q_{2}$ occurs in the nuclear scope of another quantifier $Q_{1}$, and a variable bound by $Q_{1}$ occurs in the restriction of $\mathrm{Q}_{2}$, then the existential presupposition of $\mathrm{Q}_{2}$ acts as a domain restrictor for $\mathrm{Q}_{2}$.

$$
\mathrm{Q}_{1}[R \ldots]\left[{ }_{N S} \mathrm{Q}_{2}\left[R . . x_{1} . .\right][N S \ldots]\right]
$$

b. Any other presupposition trigger in the nuclear scope of $Q_{1}$ does not act as a domain restrictor for $\mathrm{Q}_{1}$. 
The difference that (26) draws is the difference between the existential requirement that the restriction of a quantifier not be empty and other types of presuppositions. In what follows, I will first present the facts that justify the generalization in (26), and, second, I will briefly comment on the nature of the distinction drawn in (26) in light of the debate on what the nature of the non-empty domain presupposition of quantifier is.

Beaver (2001), and Beaver (1994), pointed out that presuppositions in the nuclear scope of a universal quantifier must be true of every individual in the domain of the quantifier, or, in other words, this presupposition cannot be accommodated in the restriction of the quantifier (what is called intermediate accommodation). This is illustrated in (27), from Beaver (2001): the context does not warrant the presupposition that every team members can drive, and the sentence in bold is odd.

(27) How many team members and cheerleaders will drive to the match? \# Few of the 15 team members and none of the 5 cheerleaders can drive, but every team member will come to the match in her car. So expect about 4 cars.

Below is a similar example: the context is such that the presupposition triggered by the possessive phrase his pubblication is not satisfied by every male student in the domain of quantification of the quantifier every. Similarly to $(27),(28-a)$ is infelicitous.

a. In this department, most of our male students do not have publications. \# However, every male student presented his publication at SALT.

b. In this department, most of our male students do not have publications. However, every publication by every male student was presented at SALT.

In contrast, the bold sentence in (28-b), with the inverse linking interpretation, is judged felicitous. At LF the quantifier every pubblication is in the nuclear scope of every male student; therefore, we would expect that the non-empty domain presupposition for every pubblication - i.e. that there is a pubblication by $x$ - should be satisfied by every male student in the domain. However, in a context that does not warrant the strong presupposition that every male student in the domain has a pubblication, the sentence is still fine. 


\subsection{Back to counterfactuals}

Presupposition projection in counterfactuals is just another instance of the generalization in (26). The structure in (30) is the skeleton of a one past counterfactuals, e.g. (29).

Jack is dead.

\#If Jack attended commencement this summer, he would meet the new Dean.

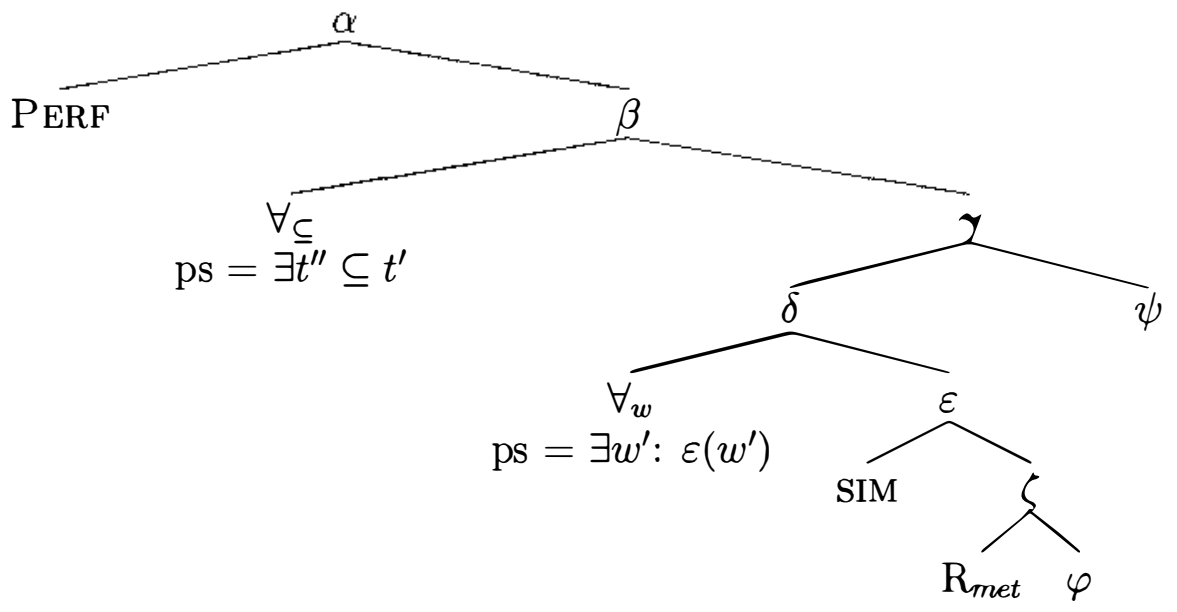

The two universal quantifiers $\forall \subseteq$ and $\forall_{w}$ are precisely in the configuration described in (26). The presupposition of the node $\beta$ will be as follows.

$$
\operatorname{ps}(\beta)=\exists t^{\prime \prime}\left[t^{\prime \prime} \subseteq t^{\prime} \wedge \exists w^{\prime}: \epsilon\left(w^{\prime}\right)\right] .
$$

As the presupposition that $x$, for $x$ a male student, has a pubblication in (28-b) does not have to hold of every male student in the domain, in (30) the presupposition that there is a $\varphi$-world accessible at $t^{\prime \prime}$ does not have to hold of every $t^{\prime \prime}$ in the domain of quantification. In these two cases, it is enough that there is a male student $x$ in our department that has a pubblication, and a $t^{\prime \prime}$ in the perfect interval such that a $\varphi$-world is accessible then, respectively. This means that a one past subjunctive conditional requires that at some time during the perfect interval there is an accessible $\varphi$-world. It does not require that at all subintervals there is an accessible $\varphi$-world: consequently, it does not require that $\varphi$ be possible at the speech time and maximally similar to the actual world. ${ }^{10}$

However, any other presuppositions in the nuclear scope of $\forall_{\subseteq}$ cannot act as a domain restrictor for the quantifier, and they must hold of every 
subinterval in the restriction of the quantifier. The nuclear scope of $\forall_{\subseteq}$ is $\gamma$, the "bare" conditional, so that $\operatorname{ps}(\gamma)$ are going to be $\operatorname{ps}(\varphi)$ and $\operatorname{ps}(\bar{\psi})$ not entailed by $\varphi$. These presuppositions are required to be true of all subintervals, including the speech time. The requirement that the presuppositions in the antecedent of a one past counterfactual must be entailed by the context follows from the fact that a bare conditional occurs in the scope of the universal quantifier over subintervals of the perfect interval.

The fact that, while $\varphi$ can be counterfactual, $\operatorname{ps}(\varphi)$ cannot, turns out to follow from the quantificational structure over times and worlds that we have assumed above. Now that we have reduced the puzzle of one past counterfactuals to the behavior of presupposiitons in quantificational structures (the generalization in (26)), one question remains: what is the nature of the contrast in (26)? What is the nature of the contrast between the no-empty domain restriction of the universal quantifier and other types of presupposition triggers, e.g. to stop? For lack of space, I must leave this question open in this paper. But let me mention that the contrast pointed out above suggests that the no-empty-domain restriction of the universal quantifier should not be viewed as a semantic presupposition, but as the result of a pragmatic condition requiring speakers to avoid making statements trivially true. ${ }^{11}$

To sum up, the presupposition of a one past counterfactal requires that for all the subintervals $t^{\prime}$ of the perfect interval, $\operatorname{ps}(\varphi)$ and $\operatorname{ps}(\psi)$ are entailed by the set of worlds metaphysically accessible at $t^{\prime}$. Since the perfect interval in a one past counterfactual includes the speech time, $\operatorname{ps}(\varphi)$ and $\operatorname{ps}(\psi)$ are required to be entailed by the set of worlds metaphysically accessible at the speech time. Following the notion of pragmatic presupposition developed in Stalnaker (1974), Stalnaker (1978), and Soames (1989), among others, an utterance of a one past counterfactual is an assertion only if this presupposition (felicity condition) is entailed by the context set. ${ }^{12}$ Since the context set is the set of worlds where what the speaker presupposes is true, an utterance of a counterfactual is an assertion only if the speaker presupposes that the presupposition of the counterfactual is true, i.e. only if the speaker presupposes that $\operatorname{ps}(\varphi)$ and $\operatorname{ps}(\psi)$ are entailed by the set of worlds metaphysically accessible at the speech time.

If my analysis is correct, the puzzle of one past counterfactual discussed in Heim (1992) reduces to the way presuppositions project in quantified structures. There is still an important question which for lack of space we set aside, i.e. why the projection facts are the way they are in general. I briefly speculated on what the reason might be, but a full investigation of 
this issue must be postponed. The point is that, given the quantificational structure I suggested, the presupposition properties of counterfactuals are indeed expected to arise.

\section{Two pasts counterfactuals}

The second puzzle of counterfactuals was instantiated by the pair below.
a. ONE PAST SUBJUNCTIVE CONDITIONAL
Jack died last year.
\#If Jack attended commencement this summer, he would meet the new Dean.
b. Two Pasts Subjunctive Conditionals
Jack died last year.
If Jack had attended commencement this summer, he would have met the new Dean.

Applying Heim (1992)'s context change potential for counterfactuals to (32-b) delivers the wrong result: since the revision of the context set is a superset of the context set, the latter was required to entail $\operatorname{ps}(\varphi)$, and (32-b) is incorrectly predicted to be infelicitous on a par with (32-a).

The proposal that I have presented above naturally accounts for the contrast between (32-a) and (32-b): the extra layer of past in two pasts counterfactuals contributes to the difference in meaning. In particular, my proposal is that a two pasts counterfactual is an bare conditional embedded under the structure of a PAST PERFECT, as shown in the simplified skeletal structure in (33).

$$
\text { 【 [TP PAST } \left.\left[\text { PerfP PERF }\left[{ }_{A s p P} \forall_{\subseteq}[[\text { WOLL } \varphi] \psi]\right]\right]\right]^{c, g, w, t}
$$

The truth-conditions for (32-b) will be as follows (abstracting away from the interpretation of the NON-PAST operator in both $\varphi$ and $\psi$ ).

【If Jack had attended commencement this summer, he would have met the new Dean $\rrbracket^{c, g, w, t}=1$ iff $\exists t^{\prime}: \operatorname{RB}\left(t^{\prime \prime \prime}, t^{\prime}\right) \wedge \forall t^{\prime \prime} \subseteq t^{\prime}\left[\forall w^{\prime}\left[w^{\prime}\right.\right.$ is metaphysically accessible from $w$ at $t^{\prime \prime} \wedge \exists t^{\prime \prime \prime \prime} \succeq t^{\prime \prime}$ s.t. it is true in $w^{\prime}$ at $t^{\prime \prime}$ that Jack will attend commencement this summer at $t^{\prime \prime \prime \prime} \wedge \neg \exists w^{\prime \prime}\left[w^{\prime \prime}\right.$ is metaphysically accessible fom $w$ at $t^{\prime \prime}$ and s.t. it is true in $w^{\prime \prime}$ at $t^{\prime \prime}$ that Jack will 
attend commencement this summer $\wedge w^{\prime \prime}$ is overall more similar to $w$ than $\left.w^{\prime}\right] \longrightarrow \exists t^{\prime \prime \prime \prime \prime \prime} \succeq t^{\prime \prime}$ s.t. it is true in $w^{\prime}$ at $t^{\prime \prime}$ that Jack will meet the Dean at $\left.t^{\prime \prime \prime \prime \prime}\right]$, defined only if $t^{\prime \prime \prime} \prec t$.

The difference between the truth-conditions in (22) and those in (34) is that whereas in the former the right boundary of the interval is the speech time, in the latter the right boundary of the interval is a past time. The contribution of the extra level of past in (32-b) is shifting the right boundary of the interval to the past. As a result, the whole interval lies in the past. As we explained above, for every subinterval $t^{\prime \prime}$ of the perfect interval, the presuppositions in the embedded conditional $(\operatorname{ps}(\varphi)$, and $\operatorname{ps}(\psi)$ not entailed by $\varphi)$ must be entailed by the set of worlds accessible at $t^{\prime \prime}$. This time, however, the speech time is not included in the perfect interval since the right boundary is a past time. Therefore, $\operatorname{ps}(\varphi)$ is not required to be entailed by the set of worlds accessible at the speech time, and the speaker is not required to presuppose that it is. ${ }^{13}$

\section{Conclusion}

Let me briefly summarize the ideas that I have discussed in this paper. I have proposed a compositional semantics for counterfactuals (subjunctive conditionals) based on the idea that a counterfactual is a bare conditional embedded under temporal and aspectual operators. Here is the summary of the proposal. Two pasts counterfactuals are characterized by the occurrence of past perfect morphology, (despite the fact that the supposition is about the future). The structure of a two pasts counterfactual is a bare conditional embedded in the structure of a universal past perfect:

$$
\llbracket\left[\left[_{T} \operatorname{PAST}\left[\operatorname{PerfP} P \text { PERF }\left[A_{s p P} \forall_{\subseteq}[\text { If } \varphi, \text { WOLL } \psi]\right]\right] \rrbracket^{c, g, w, t}\right.\right.
$$

One past counterfactuals are characterized by an occurrence of past less than their two pasts counterparts. Their structure is like that one above minus the top layer of past:

$$
\llbracket\left[\text { PerfP PERF }\left[A_{s p P} \forall_{\subseteq}[\text { If } \varphi, \text { WOLL } \psi]\right] \rrbracket^{c, g, w, t}\right.
$$

I have argued that once we unveil the quantification over times hidden in counterfactuals, their presuppositional properties can be reduced to the properties of any quantificational structure. 


\section{Appendix}

- ONTOLOGY:

$D_{t}=\{0,1\} ; D_{s}=W ; D_{<a, b>}=D_{b}^{D_{a}} ; D_{i}=T ; I_{a}=D_{a}^{W \times T}$.

- Composition Rules:

Functional Application:

$\llbracket \alpha<a, b>\beta_{a} \rrbracket^{w, t}=\llbracket \alpha \rrbracket^{w, t}\left(\llbracket \beta \rrbracket^{w, t}\right)$

Intensional Functional Application (IFA):

$\llbracket \alpha<<s a>b>\beta_{a} \rrbracket^{c, w, t}=\llbracket \alpha \rrbracket^{c, w, t}\left(\lambda w^{\prime} \cdot \llbracket \beta \rrbracket^{c, w^{\prime}, t}\right)$

T(emporal) Functional Applications (TFA):

1. $\llbracket \alpha_{<<i a>b>} \beta_{a} \rrbracket^{c, w, t}=\llbracket \alpha \rrbracket^{c, w, t}\left(\lambda t^{\prime} \cdot \llbracket \beta \rrbracket^{c, w, t^{\prime}}\right)$

2. $\llbracket \alpha_{i} \beta_{t} \rrbracket^{c, w, t}=\left[\lambda t^{\prime} \cdot \llbracket \beta \rrbracket^{c, w, t^{\prime}}\right]\left(\llbracket \alpha_{i} \rrbracket^{c, w, t}\right)$

- Derivation for

【If Jack attended commencement this summer, he would meet the new Dean $\rrbracket^{c, w, t, g}$ :

$\llbracket\left[\operatorname{PerfP} \operatorname{PERF}\left[{ }_{A s p P} \forall_{\subseteq}[\mathrm{WOLL}[\operatorname{Sim}[\operatorname{MET} \varphi]]] \psi\right]\right] \rrbracket^{c, g, w, t}$

$=($ by TFA)

$\left.\left.\left.\llbracket \operatorname{PERF} \rrbracket^{c, g, w, t}\left(\lambda t^{\prime \prime} . \llbracket \forall_{\subseteq}[\mathrm{WOLL}[\operatorname{SIM}[\operatorname{MET}[\varphi]]] \psi]\right]\right]\right] \rrbracket^{c, g, w, t^{\prime \prime}}\right)$

$=($ by lexical entry PERF)

$\left.\left[\lambda \mathrm{P} . \exists t^{\prime}: \operatorname{RB}\left(t, t^{\prime}\right) \wedge \mathrm{P}\left(t^{\prime}\right)=1\right]\left(\lambda t^{\prime \prime} . \mathbb{} \forall_{\subseteq}[\operatorname{WOLL}[\operatorname{Sim}[\operatorname{MeT} \varphi]]] \psi\right]\right]$ $\left.\rrbracket^{c, g, w, t^{\prime \prime}}\right)$

$=$ (by two applications of $\lambda$ notation)

$\exists t^{\prime}: \operatorname{RB}\left(t, t^{\prime}\right) \wedge \llbracket \forall_{\subseteq}[$ WOLL $[\operatorname{Sim}[\operatorname{MET} \varphi]] \psi] \rrbracket^{c, g, w, t^{\prime}}$

$=($ by TFA $)$

$\left.\exists t^{\prime}: \operatorname{RB}\left(t, t^{\prime}\right) \wedge \llbracket \forall \subseteq \rrbracket^{c \cdot g \cdot w \cdot t^{\prime}}\left(\lambda t^{\prime \prime \prime} . \llbracket \operatorname{WOLL}[\operatorname{SIM}[\operatorname{MET} \varphi]] \psi\right] \rrbracket^{c \cdot g \cdot w \cdot t^{\prime \prime \prime}}\right)$

$=\left(\right.$ by entry $\left.\forall_{\subseteq}\right)$

$\exists t^{\prime}: \operatorname{RB}\left(t, t^{\prime}\right) \wedge\left[\lambda \mathrm{P} . \forall t^{\prime \prime} \subseteq t^{\prime}\left[\mathrm{P}\left(t^{\prime \prime}\right)\right]\right]\left(\lambda t^{\prime \prime \prime}\right.$. 【WOLL [SIM [MET $\left.\left.\left.\varphi\right]\right] \psi\right]$ $\rrbracket^{\left.c, g, w, t^{\prime \prime \prime}\right)}$

$=$ (by two applications of $\lambda$ notation)

$\left.\exists t^{\prime}: \operatorname{RB}\left(t, t^{\prime}\right) \wedge \forall t^{\prime \prime} \subseteq t^{\prime}[\llbracket \operatorname{WOLL}[\operatorname{Sim}[\operatorname{MET} \varphi]] \psi] \rrbracket^{c . g \cdot w \cdot t^{\prime \prime}}\right]$

$=$

$\exists t^{\prime}: \operatorname{RB}\left(t, t^{\prime}\right) \wedge \forall t^{\prime \prime} \subseteq t^{\prime}\left[\llbracket \mathrm{WOLL} \rrbracket^{c, g, w, t^{\prime \prime}}\left(\llbracket \operatorname{SIM}[\operatorname{MET} \varphi] \rrbracket^{c, g, w, t^{\prime \prime}}\right)\left(\llbracket \psi \rrbracket^{c . g \cdot w \cdot t^{\prime \prime}}\right)\right.$ ]

$=($ by entries for WOLL and SIM)

$\exists t^{\prime}: \mathrm{RB}\left(t, t^{\prime}\right) \wedge \forall t^{\prime \prime} \subseteq t^{\prime}\left[\lambda \mathrm{p} . \lambda \mathrm{q} . \forall w^{\prime}\left[\mathrm{p}\left(w^{\prime}\right) \longrightarrow \mathrm{q}\left(w^{\prime}\right)\right]\right]\left(\lambda \mathrm{r} . \lambda w^{\prime \prime} \cdot \mathrm{r}\left(w^{\prime \prime}\right)\right.$ 
$\left.\left.\wedge \neg \exists w^{\prime \prime \prime}: \mathrm{r}\left(w^{\prime \prime \prime}\right) \wedge w^{\prime \prime \prime}<_{\mathrm{SIM}, w} w^{\prime \prime}\right]\left(\llbracket \operatorname{MET} \varphi \rrbracket^{c, g, w, t^{\prime \prime}}\right)\right)\left(\llbracket \psi \rrbracket^{c, g, w, t^{\prime \prime}}\right)=$ $\exists t^{\prime}: \mathrm{RB}\left(t, t^{\prime}\right) \wedge \forall t^{\prime \prime} \subseteq t^{\prime}\left[\lambda \mathrm{p} . \lambda \mathrm{q} . \quad \forall w^{\prime}\left[\mathrm{p}\left(w^{\prime}\right) \longrightarrow \mathrm{q}\left(w^{\prime}\right)\right]\right]\left(\lambda w^{\prime \prime} . \llbracket \mathrm{MET}\right.$ $\left.\varphi \rrbracket^{c, g, w, t^{\prime \prime}}\left(w^{\prime \prime}\right) \wedge \neg \exists w^{\prime \prime \prime}: \llbracket \operatorname{MET} \varphi \rrbracket^{c, g, w, t^{\prime \prime}}\left(w^{\prime \prime \prime}\right) \wedge w^{\prime \prime \prime}<\operatorname{SIM}, w w^{\prime \prime}\right)\left(\llbracket \psi \rrbracket^{c, g, w, t^{\prime \prime}}\right)$ $=$ (by the entries for MET and $\varphi$ combined by TFA1 and IFA; the entry for $\psi$; and further applications of $\lambda$-notation)

$\exists t^{\prime}: \operatorname{RB}\left(t, t^{\prime}\right) \wedge \forall t^{\prime \prime} \subseteq t^{\prime}\left[\forall w^{\prime}\left[w^{\prime}\right.\right.$ is metaphysically accessible from $w$ at $t^{\prime \prime} \wedge \exists t^{\prime \prime \prime} \succeq t^{\prime \prime}$ s.t. it is true in $w^{\prime}$ at $t^{\prime \prime}$ that Jack will attend attend commencement this summer at $t^{\prime \prime \prime} \wedge \neg \exists w^{\prime \prime \prime}$ : [ $w^{\prime \prime \prime}$ is metaphysically accessible fom $w$ at $t^{\prime \prime}$ and s.t. it is true in $w^{\prime \prime \prime}$ at $t^{\prime \prime}$ that Jack will attend commencement this summer $\wedge w^{\prime \prime \prime}$ is overall more similar to $w$ than $\left.w^{\prime}\right] \longrightarrow \exists t^{\prime \prime \prime \prime} \succeq t^{\prime \prime}$ s.t. it is true in $w^{\prime}$ at $t^{\prime \prime}$ that Jack will meet the new Dean at $\left.\left.t^{\prime \prime \prime \prime}\right]\right]$

\section{Aknowledgments}

I am very grateful to Bridget Copley, Kai von Fintel, Irene Heim, Sabine Iatridou, Jeff King, Bob Stalnaker, Jason Stanley, Arnim von Stechow, Zoltán Szabó, and Richmond Thomason for discussions, and extensive comments at different stages of this work. All mistakes and omissions are mine.

\section{Notes}

${ }^{1}$ This is an oversimplification of Stalnaker's ideas about the context. See Stalnaker (1975), Stalnaker (1978), Stalnaker (2002) for a detailed discussion of the notions of context and common ground.

${ }^{2}$ The definition of sim in Heim (1992) is as follows:

(i) $\quad \operatorname{Sim}_{w}(\mathrm{p})=\left\{w^{\prime} \in W: w^{\prime} \in p\right.$ and $w^{\prime}$ is as similar to $w$ as any other $p$-world $\}$.

${ }^{3}$ For any conversational background $f$, we can define the corresponding accessibility relation $R_{f}$ as follows:

$$
R_{f}:=\lambda w^{\prime} . \forall p\left[f(w)(p)=1 \rightarrow p\left(w^{\prime}\right)=1\right] .
$$

${ }^{4}$ For the notion of overall similarity, see Lewis (1979).

${ }^{5}$ For a thorough analysis of SOT phenomena such as the one illustrated in the text, see Ogihara (1996), Abusch (1997), Stechow (2003), and many others.

${ }^{6}$ This is basically the structure in (2). In fact, elsewhere I have suggested that the structure of what I call here "bare" conditionals is the structure of (at least some) indicative conditionals. Very briefly, indicative conditionals are not embedded under a temporal/aspectual structure. Since the time parameter of the accessibility relation is not manipulated by temporal and aspectual operators, it takes the speech time as its value. 
${ }^{7}$ See Fintel and Iatridou (2002) for their definitions of left and right boundaries. Intuitively, RB and LB are the leftmost and rightmost subintervals of the perfect interval, respectively.

${ }^{8}$ According to Fintel and Iatridou (2002), whether the universal quantifier is needed or not depends on whether the relevant predicate has the subinterval property of not.

${ }^{9}$ See Ippolito (2003a) for more discussion of this point.

${ }^{10}$ In principle, there could be a world $w^{\prime}$ accessible from the actual world $w$, identical to the $w$ up to the speech time where Jack died when he actually did and will attend commencement this summer: this will have to be a world where Jack comes back from the dead sometime between now and commencement. This world differs from the actual world in a fundamental way, in that the actual laws are violated. Strengthening Lewis (1979)'s definition of similarity, worlds where violations of actual laws occur are never selected by the similarity function.

${ }^{11}$ Thanks to Danny Fox (p.c.) for this suggestion. If the no-empty-domain restriction is not a presupposition, then we do not expect it to project the same way that other presuppositions - such as the one triggered by to stop - are. See Abusch and Rooth (to appear) and references cited there for a discussion of this issue with respect to strong and weak determiners.

${ }^{12}$ An utterance is a successful assertion only if it devides the context set in worlds where the proposition is expresses is true and worlds where it is false.

${ }^{13} \mathrm{As}$ for why two pasts counterfactuals like (32-b) are felicitous just in case the speaker believes $\varphi$ to be impossible, I have argued elsewhere that is it follows from a principle requiring speakers to maximize presuppositions. See Ippolito (2003b), Ippolito (2003a) for more on two pasts counterfactuals.

\section{References}

ABusch, D. (1997): "Sequence of Tense and temporal de re," Linguistics and Philosophy.

ABUSCH, D., AND M. Rooth (to appear): "Empty-domain effects for presuppositional and non-presuppositional determiners," in Context Dependence in the Analysis of Linguistic Meaning, ed. by H. Kamp, and B. Partee. Elsevier Publishers.

BEAvER, D. (1994): "When variables don't vary enough," in Semantics and Linguistics Theory 4, ed. by L. S. Mandy Harvey, Cornell. CLC Publisher.

- (2001): Presupposition and Assertion in Dynamic Semantics. CSLI Publications and FoLLI.

Dowty, D. (1979): Word Meaning and Montague Grammar. Reidel, Dordrecht.

Fintel, K. V., and S. IAtridou (2002): "Since since," MIT, ms.

Heim, I. (1982): "The Semantics of Definite and Indefinite Noun Phrases," 
Ph.D. thesis, University of Massachusetts, Amherst, MA.

- (1983): "On the Projection Problem for Presuppositions," in Proceedings of WCCFL, vol. 2, pp. 114-125.

- (1992): "Presupposition Projection and the Semantics of Attitude Verbs," Journal of Semantics, 9, 183-221.

Ippolito, M. (2003a): "On the Semantic Composition of Subjunctive Conditionals," Universität Tübingen, ms.

- (2003b): "Presuppositions and Implicatures in Counterfactuals," Natural Language Semantics, 11, 145-186.

Karttunen, L. (1974): "Presupposition and linguistic context," Theoretical Linguistics, I, 181-194.

Kratzer, A. (1981): "The Notional Category of Modality," in Words, Worlds, and Contexts, ed. by H.-J. Eikmeyer, and H. Rieser. de Gruyter, Berlin.

- (1991): "Modality," in Semantics. An International Handbook of Contemporary Research, ed. by A. v. Stechow, and D. Wunderlich. De Gruyter, Berlin.

LEwis, D. (1973): Counterfactuals. Harvard University Press, Cambridge, MA.

(1979): "Counterfactual Dependence and Time's Arrow," Noûs, 13.

Musan, R. (1997): "Tense, Predicates and Lifetime Effects," Natural Language Semantics, pp. 271-301.

Oginara, T. (1996): Tense, Attitudes, and Scope. Kluwer Academic Publishers.

SoAmes, S. (1989): "Presupposition," in Handbook of Philosophical Logic, vol. IV, pp. 553-617. Reidel, Dordrecht.

Stalnaker, R. (1974): "Pragmatic Presuppositions," in Semantics and Philosophy, ed. by M. Munitz, and P. Unger, pp. 197-213. New York University Press, New York.

_ (1975): "Indicative Conditionals," Philosophia, 5, 269-286.

(1978): "Assertion," in Syntax and Semantics: 9, ed. by P. Cole. Academic Press, New York.

- (2002): "Commn Ground," Linguistics and Philosophy, 25, 701721.

Stechow, A. V. (2003): "Binding by Verbs: Tense, Person and Mood under Attitudes," in Proceedings of NELS 33. 